\title{
Proposals for Upgrading the Teaching of Geotechnical Courses
}

\author{
Nikolaos Alamanis ${ }^{1, *}$, Grigorios Papageorgiou ${ }^{1}$, Ioannis Chouliaras ${ }^{1}$, Nikolaos Xafoulis ${ }^{1}$, \\ Spyridon Kotsopoulos ${ }^{1}$, Evangelia Farsirotou ${ }^{2}$, Konstantinos Lazogiannis ${ }^{3}$, Georgios Soulis ${ }^{1}$ \\ ${ }^{1}$ General Department of Larissa, University of Thessaly, Greece \\ ${ }^{2}$ Department of Ichthyology \& Aquatic Environment, School of Agricultural Sciences, University of Thessaly, Greece \\ ${ }^{3}$ Department of Geography - Climatology, Department of Geology \& Geoenvironment, National and Kapodistrian University of Athens, \\ Greece
}

Received January 19, 2020; Revised March 27, 2020; Accepted April 19, 2020

Copyright $\bigcirc 2020$ by authors, all rights reserved. Authors agree that this article remains permanently open access under the terms of the Creative Commons Attribution License 4.0 International License

\begin{abstract}
The purpose of this paper is to prepare proposals resulting from questionnaire research, in which both undergraduate students took part in the course "Soil Mechanics Laboratory" of the Department of Civil Engineering (Academic Year 2018-2019) and Forestry Department (A.Y. 2002-2003) and postgraduate students in the courses "Advanced Geotechnics-Simulations" and "Road Infrastructure Harmonization in the Environment" of the Postgraduate Studies Programme "Advanced Environmental Management Technologies in Engineering Works" of the General Department of Larissa of the University of Thessaly, with the ultimate goal of upgrading and modernizing the teaching of the above and similar courses. The general purpose of teaching in geotechnical courses is that students acquire knowledge necessary for the design and construction of geotechnical projects, in collaboration with other civil engineering specialties. The research of the teaching strategy concerns about the design of the questionnaires in conjunction with the objectives of the course. According to the curriculum, geotechnical courses aim to enable students to apply the methodologies for calculating the physical characteristics and the mechanical properties of the soil. Finally, the responses of the undergraduate and postgraduate students were evaluated, and useful conclusions emerged, which can positively contribute to the qualitative upgrading and the modernization of the teaching process of the above courses.
\end{abstract}

Keywords Educational Engineering, Geotechnical Courses, Soil Mechanics \& Asphalt Laboratory, Teaching Improvement.

\section{Introduction}

Until recently, the civil engineering profession and studies were booming worldwide, profiting from the favourable socio-economic conditions that prevailed in the second half of the 20th century. The beginning of the 21 st century however, signalled a sharp change. The financial crisis led many countries into recession, which reduced infrastructure expenditure [1] and increased unemployment in the sector [2]. In a significant number of developed countries, after many years of construction, any new infrastructure planning must overcome a time consuming and cumbersome permit issuance process.

On the other hand, many other countries have entered their development phase and are promoting heavy investment in infrastructure, as market globalization advances rapidly. It should be emphasized that there is still a strong need for new infrastructure in the world. To cope with the drastic changes of the socio-economic environment, the civil engineering profession must intelligently adapt [3].

Since geotechnical engineering is the connecting branch of all Civil Engineering specialties, it becomes obvious that upgrading the teaching of the respective courses generally improves the quality of the entire Civil Engineering field. Geotechnical courses, in addition to the learning process of calculating the physical and mechanical properties of the soil as well as the study of geotechnical projects, are designed to enable students to develop social skills that include cooperation, communication, mutual assistance, organisation and responsibility [4]. Thus, the sociability of teaching is reflected in the cultivation of those skills that promote science and the practice of daily life [5].

This project aims at activating the students and 
integrating them into an ever-changing scientific-social field as well as to prompt other geotechnical engineering instructors to implement research-based instructional interventions in their courses and contribute to the literature of geotechnical engineering education by sharing their work and experiences.

Finally, the research process, which aimed at involving as many students as possible in the educational process to have a reliable sample of responses, closes with conclusions that may be of interest to the wider educational community. A historical review of the evolution of engineering and engineering education leads to the conclusion that sustainability in design and construction requires the engineer to approach nature with imagination and humility [6].

\section{Materials and Methods}

As mentioned earlier, the research conducted aimed at involving as many students as possible to ensure a reliable sample size, considering the number of students at the University of Thessaly. The method selected for this purpose was the use of closed question questionnaires, as these tend to allow researchers to collect reliable, in-depth data that can be interpreted easily, both quickly and economically. Moreover, information collected can be easily converted into quantitative data, in order to statistically analyse the data [7].

Specifically, questionnaires constitute an effective medium through which behaviour, attitudes, preferences, opinions, and intentions can be quantified, with the data being sourced from relatively large numbers of subjects, in an economical and swift manner. Closed question questionnaires follow preset standardization, as all participants are asked the same questions in the same order. This implies that a closed question questionnaire-based survey can be replicated/ repeated with ease, to verify its reliability. Consequently, following research can utilize the questionnaire data to check for consistency. Open question questionnaires allow researchers to gather rich qualitative data as open questions allow for elaboration on the answers provided by the respondents. Consequently, this allows the researcher some insight into the motive behind a certain attitude towards the part of the respondent [8]

\subsection{The Questionnaires}

The questionnaires used were three distinct ones. The first one concerning the Soil Mechanics Laboratory is for undergraduates in academic years 2002-2003 and 2018-2019. Following were two questionnaires aimed at postgraduate Master's students, titled Advanced Geotechnics and Harmonization of Road Infrastructure in the Environment.
The first questionnaire titled Soil Mechanics Laboratory Evaluation contained thirteen closed questions and one open end, where students were asked to provide their general opinion on the lesson and the teaching staff. The second questionnaire titled Advanced Geotechnics contained five closed questions and one open question, where students were asked to provide their opinion on what they would change, if they were in the position of the teacher. Finally, the third questionnaire, titled Harmonization of Road Infrastructure in the Environment, contained 9 closed questions and two open questions in which the former asked for clarification depending on the response to a closed question, and the latter asked for suggestions for improvement in the lesson.

\subsection{Data Collection Tactics}

Data was collected thrice. Regarding the first questionnaire, responses were first collected during the 2002-2003 academic year, from 53 undergraduate students attending 'Soil Mechanics Laboratory', a geotechnical course at the Forestry Department of the University of Thessaly, and next during the 2018-2019 academic year, from 90 undergraduate students attending the same course at the Department of Civil Engineering of the University of Thessaly. Regarding the second and third questionnaires, responses were collected during the 2018-2019 academic year, from 15 postgraduate students attending the courses "Advanced Geotechnics-Simulations" and "Road Infrastructure Harmonization in the Environment" of the Postgraduate Studies Programme "Advanced Environmental Management Technologies in Engineering Works" of the General Department of Larissa of the University of Thessaly.

\subsection{Data Selection Rationale}

It should be noted that the questionnaire was used in two distinct times, first during the 2002-2003 Academic Year and second during the 2018-2019 Academic Year. More specifically, the undergraduate body of students attending one specific course was targeted both in 2002-2003 and in 2018-2019, while postgraduate students were queried in 2018-2019 only.

Regarding the undergraduate student responses, the rationale included obtaining an extrapolated view of how student opinion might have shifted, when studying two data endpoints. Furthermore, analysis of the whole body of responses might enable the teaching staff to enact changes in order to further improve the teaching methodology of said course.

\subsection{Evaluation of Responses}

As has already been mentioned in the formulation of the 
questionnaires, various types of questions were used, and several factors were considered to improve the teaching of geotechnical courses. This section presents circular diagrams with the responses to the questionnaires related to the undergraduate Laboratory course by a total of 53 students of the Department of Forestry (questionnaire given for the academic year 2002-2003). The responses to the questionnaires in the same course of the undergraduate curriculum of the Department of Civil Engineering of Larissa are then presented in the same way (A.Y. 2018-2019) by a total of 90 students and comparisons and annotations of the responses are made.

\subsubsection{Undergraduate Courses (Lab Evaluation)}

Regarding the interest of the subject of laboratory exercises and its practical application according to the students' responses, in the academic year 2002-2003 the majority is not completely satisfied. On the contrary, regarding the questionnaires during the academic year $2018-2019$, the vast majority is very satisfied (Fig. 1). This may be explained by the upgrading of the laboratory equipment and the modernizing of the laboratory exercises (teaching material).

Following this, regarding the organization of the soil engineering laboratory and its classification compared with the other laboratories of the former Technological Educational Institute of Thessaly (T.E.I.) (now Curriculum of the University of Thessaly), there has been a significant improvement over the years as shown by the students' responses (Fig. 2).

Finally, the overwhelming majority of students in the Department of Forestry and the Department of Civil Engineering believe that an educational excursion to project sites is related to the laboratories contributes to the upgrading of the course.
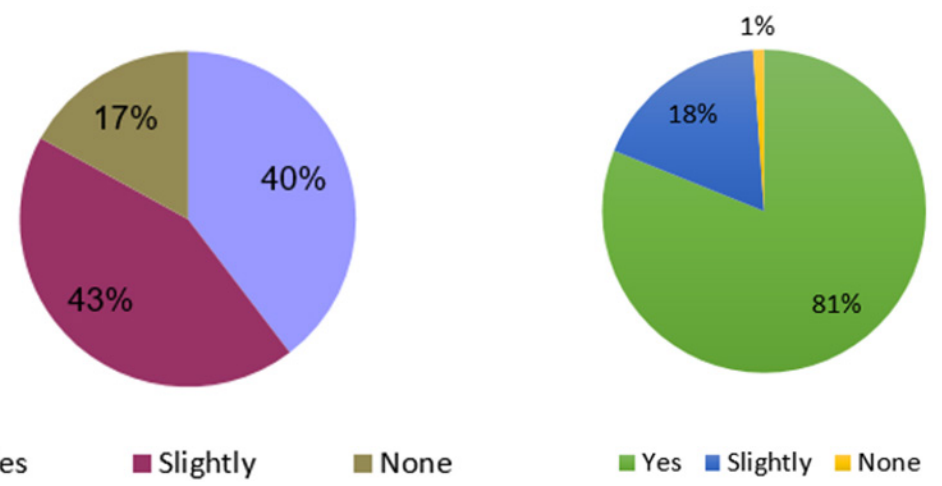

Figure 1. Degree of students' satisfaction with the subject and practical application of the laboratory exercises during the academic years 2002 2003 (left) and 2018 - 2019 (right)
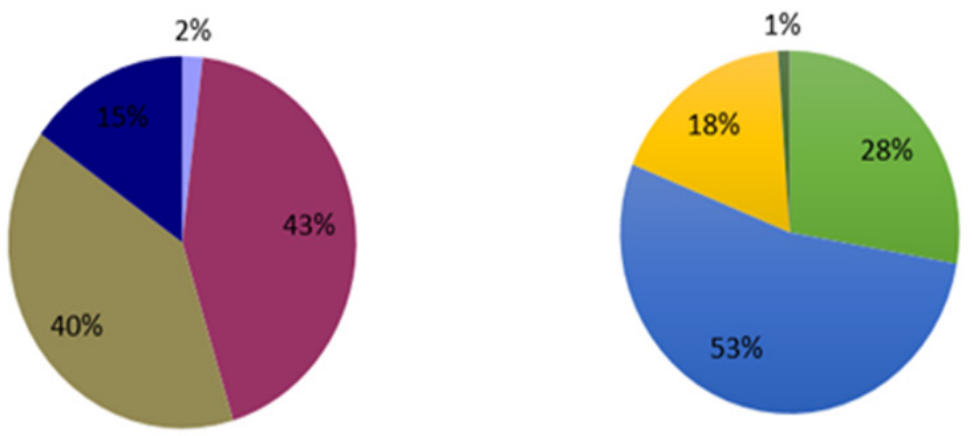

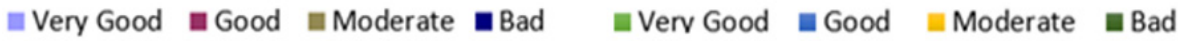

Figure 2. Organization and classification of a soil engineering workshop during the academic years $2002-2003$ (left) and 2018 - 2019 (right) 

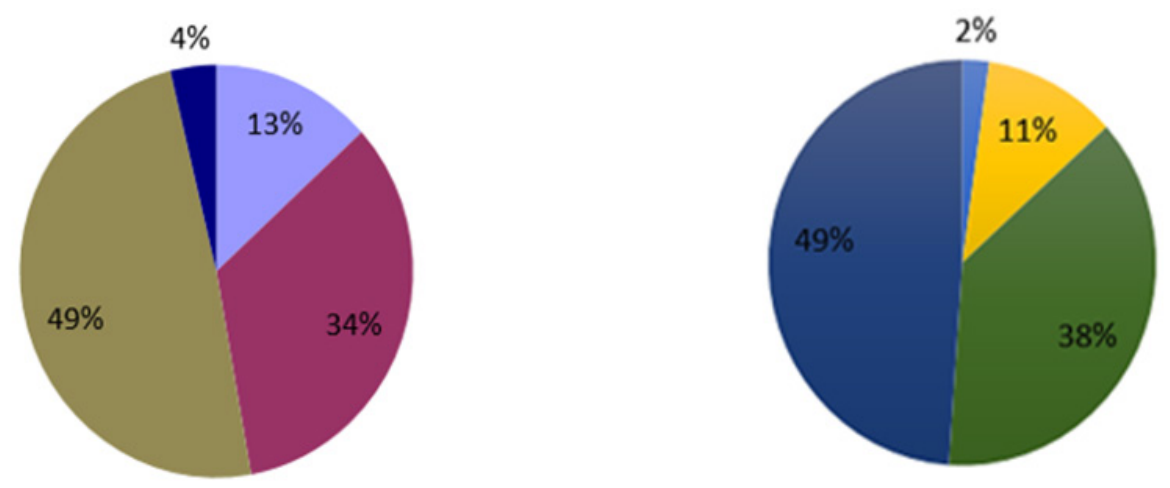

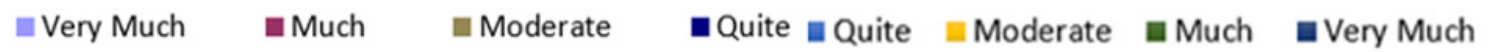

Figure 3. Personnel evaluation of the Soil Mechanics Laboratory during the academic years 2002 - 2003 (left) and 2018 - 2019 (right)

\subsubsection{Undergraduate Curricula (Teacher Assessment)}

The evaluation of the laboratory staff was based on the basic criteria such as the knowledge ability and the communicability of the subject of the laboratory lesson by the teacher and the interest and support the staff provided to students during the laboratory exercises.

Based on the above criteria, the following graphs were obtained (Fig. 3).

The students' responses show that they are largely satisfied with the staff of the laboratory in the academic year 2002 - 2003, while in the academic year 2018 - 2019 the overwhelming majority are very satisfied.

\subsection{Postgraduate Programme Studies}

This section presents the results of the use of questionnaires by a total of 15 postgraduate students attending the Postgraduate Programme Studies in Advanced Environmental Management Technologies in Engineering Works at the University of Thessaly for the courses "Advanced Geotechnics - Simulations" and "Road Infrastructure Harmonization in the Environment".

\subsubsection{Advanced Geotechnical - Simulations}

The evaluation of the postgraduate course was based on the following basic criteria:

i). Postgraduate students' view of the necessity of teaching the above course in this programme as well as of the adequacy of the teaching hours ( 2 hours) available to cover the syllabus.

ii). The utility of teacher communication with the postgraduate students and its evaluation.

iii). Conducting research work / studies related to the subject after the end of the course teaching.

Based on the above criteria, the following graphs were obtained (Fig. 4, 5, $6 \&$ 7).

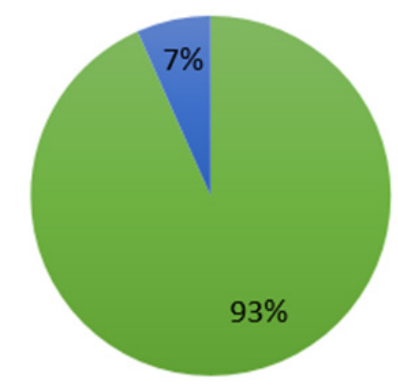

Necessary A Little Necessary

Figure 4. Necessity of the course in the Postgraduate Programme.

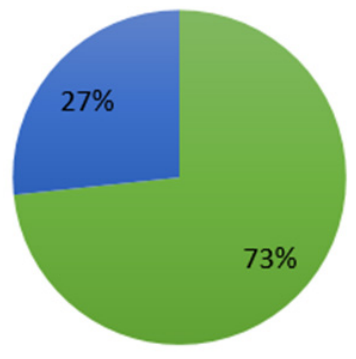

a High $\square$ Moderate

Figure 5. Satisfaction with the lesson hours.

From the above figures it emerged that the students consider it necessary to have the course in this postgraduate programme because it is directly related to the management of environmental issues using modern technologies (Fig.4) while at the same time the hours that cover the teaching of the lesson are presented as adequate (Fig.5). 


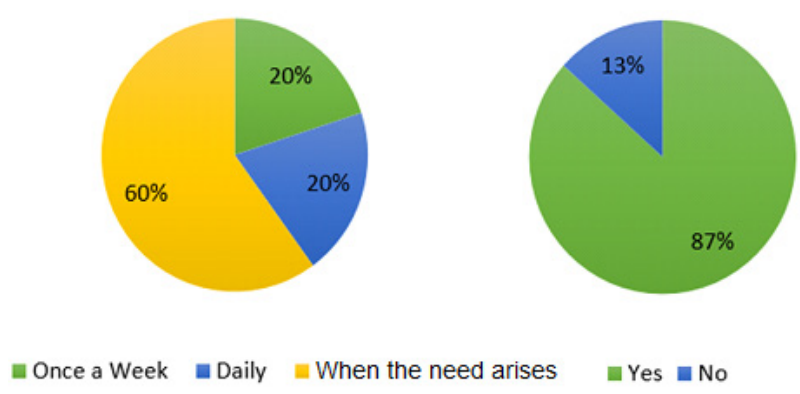

Figure 6. Student communication level - teacher (left) and need for teacher evaluation (right)

According to the above figure (Fig. 6), the majority of students are satisfied with the ability to communicate with the teacher whenever necessary, while a significant proportion wants weekly or daily communication. Also, most of them want to evaluate the teacher at the end of each semester (before exams).

Finally, the majority of students think that they will be able to carry out research projects / studies related to the subject as shown in the responses presented in the figure below (Fig.7).

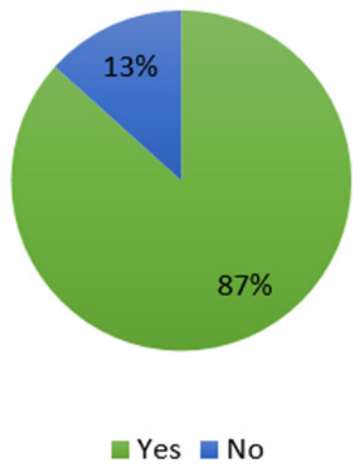

Figure 7. Ability to implement a research project.

\subsubsection{Road Infrastructure Harmonization in the} Environment

This section presents the students' responses to the course "Road Infrastructure Harmonization in the Environment". The evaluation of the postgraduate course was based on the postgraduate students' view of how the lesson was taught in the particular programme, how the exam was conducted as well as the teacher's behaviour towards the students. According to the students' responses, it was found that most of them are quite satisfied with the way the lesson is taught (Fig. 8). In addition, the overwhelming majority find that the teacher's behaviour towards them is excellent and very good (Fig.9). Regarding the teaching method, students find that compulsory tasks (projects) would greatly improve understanding the lectures (Fig.10), while wish that there be neither mid-term nor oral examination before finals (Fig. 11).

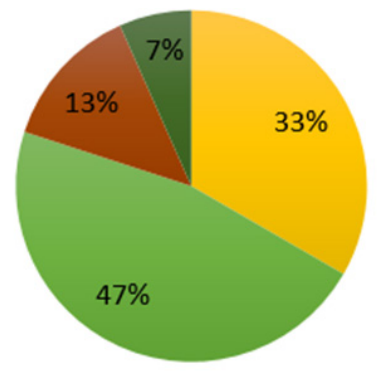

घ Absolutely $\square$ Very Much $\square$ Quite $\square$ Slightly $\square$ Least $\square$ None

Figure 8. Satisfied with the way the lesson is taught

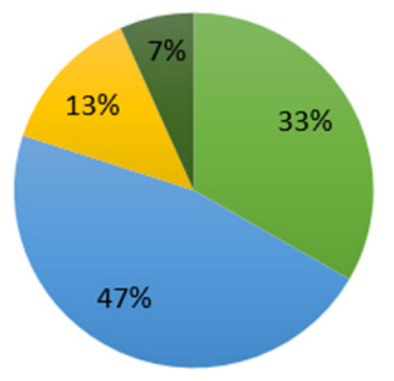

$$
\begin{array}{lll}
\text { Excellent } & \text { Very Good } & \text { Good } \\
\text { Moderately } & \square \text { Bad } & \text { Unacceptable }
\end{array}
$$

Figure 9. Degree of satisfaction with teacher behavior

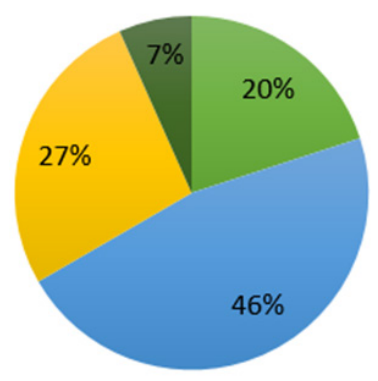

absolutely $\square$ Very Much $₫$ Quite $\square$ Slightly $\square$ Least $₫$ None

Figure 10. Necessity of compulsory tasks 


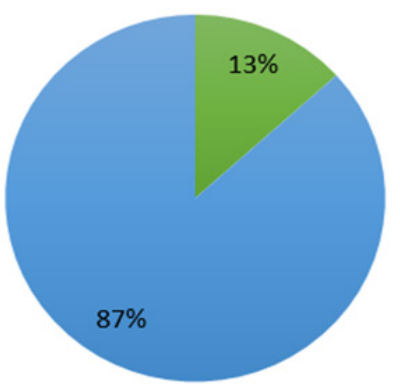

$\square$ Yes $=$ No

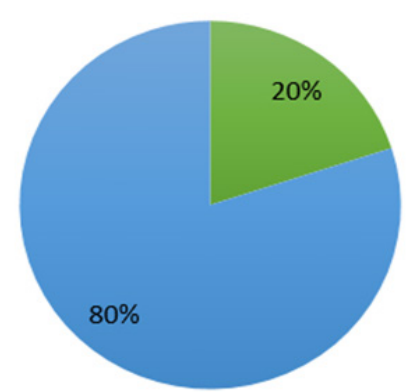

Yes $=$ No

Figure 11. Necessity of mid-term examination (left), oral examination (right)

\section{Conclusions}

Upon completion of this study, and evaluating the responses of undergraduate students of the Department of Forestry and of the Department of Civil Engineering of Larissa regarding the soil mechanics laboratory, as well as the responses of the postgraduate students of the M.Sc. programme "Advanced Environmental Management Technologies in Engineering Works", the following conclusions become apparent:

i). The completion of questionnaires by students every year during the respective courses and their evaluation by the teachers helps to improve the teaching of the courses.

ii). Educational field trips to various projects of geotechnical interest are necessary in order to increase students' knowledge and judgment and at the same time to achieve the upgrade of the course.

iii). The modernization of the laboratories (both the equipment and the teaching material) improves the educational process.

iv). The material from the use of questionnaires can be useful and encourage engineering instructors to contribute their work to the communal instructional resources.

v). Based on the belief that teaching is and should be a collective venture in order to achieve improvement in education and taking into account the results of research on teaching and learning [9], the use of open and closed type questionnaires in geotechnical courses contributes positively to the above.

vi). In their overwhelming majority, postgraduate students converge on the necessity of compulsory tasks (projects) as an important element of the learning process in order to improve their ability to understand sufficiently the teaching subject.

vii). Most students believe that after completing their courses they will be able to successfully participate in studies and research work in the field of geotechnical engineering.

viii). Finally, from the student responses and from the fact that those involved in this research appear to be particularly satisfied with the teaching of the courses, it is evident that most of the course objectives have been achieved.

\section{Changes Implemented So Far}

Following the conclusions reached through the research conducted by the authors, several changes/improvements have been implemented so far, thus improving the teaching rendered to students. More specifically:

- Depending on the syllabus, the technique that is considered to produce the best learning outcomes is selected, thus motivating the students' interest. The teacher, by using different teaching techniques, adapts to the learning needs, and utilizes different ways of learning to better suit the students, who, in turn, practice an alternative modus of learning.

- Educational excursions were approved in the curriculum, and in each module of the course along with the necessary theoretical background, a corresponding geotechnical example of construction or geotechnical failure is presented. Specifically, the students were presented with examples of projects that showed failures both during their construction period and during their later years, located in various areas throughout Greece, and consequently in areas familiar to students, but also from around the world.

- Moreover, there is increased interdisciplinary cooperation, where teachers from different fields of Geotechnics jointly explore and guide students towards a more spherical perspective of this scientific field.

\section{Suggestions}

Considering the conclusions of the survey analysis, the authors of this paper believe that several suggestions can be put forth, in order to improve the overall quality of Geotechnics curriculum and to prepare it to meet future demands. These suggestions are as follows:

i). Provide students with the flexibility to self-organize as they deem necessary, in order to tackle class work 
requirements, such as papers, experiments, etc, as this will provide the class with a higher quality, diversified results set, compared with work done individually, with the added benefit of accommodating an overwhelming number of creative students who do not learn in the classic way and fail. Learning as a process needs to be put at the heart of education moving us away from the traditional educational enterprise [10].

ii). Provide students with the opportunity to participate in field trips organized by the school, for them to experience in vita reali and in context the theoretical knowledge they gained in class [11].

iii). Hold regular class assessment meetings with the participation of the teaching staff and a delegation of the student body, in order to gain insight into the overall reception of the curriculum by the students, and be prepared to take into consideration for evaluation and future assimilation into the teaching module any suggestion made during these meetings.

iv). Allow anonymous feedback on both the quality of the lesson delivered by teachers and the material delivered, at the end of the semester.

v). Expose undergraduates to the multifaceted nature of Geotechnics, so as to spark ideas for how to expand on and improve the scientific field they are studying, especially after completing the main course of study.
[6] Schexnayder, C. \& Anderson, S. Construction engineering education: history and challenge. Journal of Construction Engineering and Management, Vol. 10, No.137, pp.730-739, 2011.

[7] Bradburn, N., Sudman, S. and Wansink, B. Asking Questions. John Wiley \& Sons, Inc., ISBN 0-7879-7088-3, 2014.

[8] McLeod, S. A. Questionnaire: Questionnaire: Definition, Examples, Design and Types. Simply psychology (2018). Available: www.simplypsychology.org/questionnaires.htm 1 [Accessed 2020-02-29]

[9] Pantazidou, M. \& Kandris K. Creating an Online Version of an Environmental Geotechnics Course: Pedagogical Opportunities SFGE 2016 - Shaping the Future of Geotechnical Education. International Conference on Geo-Engineering Education - TC 306 20-21 October, Belo Horizonte, Minas Gerais, Brazil, ISSMGE, 2016.

[10] Bernold, L.E. Paradigm shift in construction education is vital for the future of our profession. Journal of Construction Engineering and Management, Vol. 5, No. 131, pp. 533-539, 2005.

[11] Harackiewicz, J., Smith, J \& Priniski, S. Interest Matters, Policy Insights from the Behavioral and Brain Sciences, Vol. 3, No. 2, pp. 220-227, 2016.

\section{REFERENCES}

[1] Construction permit index overview - Statistics Explained. Online Available: https://ec.europa.eu/eurostat/statistics-explained/index.php/ Construction_permit_index_overview. [Accessed 2020-01-03]

[2] Onodugo, V. A., Obi, K. O., Anowor, O. F., Nwonye, N. G., \& Ofoegbu, G. N. Does public spending affect unemployment in an emerging market? Risk governance \& control: Financial markets \& institutions, Vol. 7, No. 1, pp. 32-40, 2017.

[3] Lambropoulos S., Pantouvakis J.P. \& Marinelli M. Reforming civil engineering studies in recession times. Procedia - Social and Behavioral Sciences, 119776 - 785, Published by Elsevier Ltd., 2014.

[4] Pantazidou, M. The Scholarship of Teaching: A Case in Environmental Geotechnics, In: Inquiries into European Higher Education in Civil Engineering, 9th Vol., Erasmus Thematic Network: European University Civil Engineering Education and Training (EUCEET), 125-152, 2010.

[5] Kallioglou, P. \& Vairamidou, S. Contemporary Teaching Approaches for the Development of Social Skills - The Example of Application in Geotechnical Engineering. Proceedings of the Hellenic Institute of Applied Education and Training (Hellenic Institute of Applied Pedagogy and Education), 6th Panhellenic Congress, October 1-9, 2012. 